\title{
ACESSIBILIDADE DIGITAL EM FOCO: RELATO DE UMA EXPERIÊNCIA
}

\section{DIGITAL ACCESSIBILITY IN FOCUS: REPORTING AN EXPERIENCE}

Vilma Villarouco, D.Sc.

\begin{abstract}
Apresenta-se neste artigo a experiência que vem sendo desenvolvida na disciplina de acessibilidade digital, do Programa de Pós Graduação em Design, da Universidade Federal de Pernambuco. Os estudantes que entram na disciplina sem conhecimentos de acessibilidade digital, objetos de aprendizagem (OA) e gamificação, vem apresentando resultados muito satisfatórios, quando produzem protótipos de OA `s, acessíveis e gamificados. A disciplina é ministrada em parceria com a UFSC e a UFPR, através do Grupo de Estudo de Ambiente Hipermídia voltado ao processo de Ensino-Aprendizagem.
\end{abstract}

Palavras chave: Objetos de aprendizagem, acessibilidade digital, gamificação.

This article presents the experience that is developed in the digital accessibility discipline of the Post Graduate Program in Design, Federal University of Pernambuco. Students without knowledge aboutf digital accessibility, objects of learning (OA) and gamification, courses the discipline and have presented very satisfactory results, when they produce prototypes of $O A ` s$, accessible and gamified. The course is taught in partnership with UFSC and UFPR, through the Study Group on the Hypermedia Environment focused on the TeachingLearning process.

Keywords: Objects of learning, digital accessibility, gamification 


\section{| Introdução}

Este texto apresenta o tema tratado na Mesa Redonda Acessibilidade e projeto inclusivo em sistemas digitais, durante o CINAHPA 2017 em Florianópolis.

O trabalho apresentado no congresso Internacional de Ambientes Hipermídia para Aprendizagem, aborda a experiência da Disciplina de Acessibilidade Digital, no Programa de Pós-graduação em Design da UFPE, com uma primeira turma no primeiro semestre de 2016, e, a segunda experiência em andamento, neste primeiro semestre de 2017. As duas turmas contam com oito estudantes cada.

No contexto da Acessibilidade Digital, inserimos o estudo e desenvolvimento de Objetos de Aprendizagem, tratando de temas diversos, que possuam as características de serem acessíveis e atrativos, que tragam em sua essência os princípios do Design Universal e que motivem os usuários à sua utilização.

O objeto de aprendizagem (OA), sendo entendido como: "qualquer entidade digital, ou não digital, que pode ser usada, reutilizada ou referenciada durante o aprendizado suportado pela tecnologia (IEEE LTSC, 2010 apud MACEDO, 2010, p.81)”, deve ser utilizado em contextos onde se busca aculturar-se de um ou mais temas, sendo adequado principalmente aos Ambientes Virtuais de Aprendizagem (AVAs), inseridos conforme as necessidades do ambiente e do conteúdo a ser viabilizado. No sentido da inclusão, devem ser providos elementos da acessibilidade para meios digitais.

A EAD (Educação à Distância) com fins de inclusão de pessoas com deficiência tem sido desenvolvida, ainda com dificuldades. Em uma busca realizada através de Revisão Sistemática de Literatura e dos mecanismos mais usados na internet, identifica-se que ainda são reduzidos os resultados encontrados, diante do grande problema que se tem instalado.

Esta modalidade de ensino, com a expansão das tecnologias educacionais, faz uso de materiais digitalizados, com todos os tipos de mídias digitais, em diferentes graus de interatividade, disponibilizados em sistemas de apoio como Ambientes Virtuais de Aprendizagem (AVAs), Sistemas Tutoriais Inteligentes (STIs), e-books, Sistemas Hipermídia Adaptativos Educacionais (SHAEs), vídeo-aula, etc.

No Brasil as questões da Inclusão Digital desenvolveram-se em um contexto mais afeito à inclusão social, ao planejamento e desenvolvimento de mecanismos de inclusão das classes menos favorecidas ao ciberespaço, às tecnologias digitais e ao acesso às redes sociais.

São ainda poucos os trabalhos que se referem à incorporação das pessoas com deficiência no foco de atenção no desenvolvimento de Ambientes Virtuais de Aprendizagem a fim de torna-los Inclusivos (AVA Inclusivo). Esses ambientes apresentam em sua conceituação inicial, a capacidade de permitir a pessoas com algumas deficiências limitadoras da comunicação oral e escrita, seu uso com autonomia e interatividade. O ensino inclusivo precisa trabalhar com a possibilidade de independência das pessoas com deficiência ao acessar os ambientes virtuais, tanto em ambientes colaborativos presenciais quanto da adoção dos espaços virtuais no aprendizado de conteúdos diversos.

A partir dessas constatações, a disciplina foi conduzida, inicialmente familiarizando os estudantes com os OAs, focando estudos dos elementos, diretrizes e critérios para a elaboração de OAs acessíveis, para em seguida, lançar os conceitos e estratégias da gamificação, com vistas a conferir ao protótipo planejado, características de motivação ao usuário.

\section{Contexto do trabalho desenvolvido}

A proposta de oferecer uma disciplina voltada aos estudos e elaboração de artefatos digitais que fossem acessíveis, foi na realidade, gestada desde a realização do meu estágio pós doutoral, no Programa de Pós Graduação em Engenharia e Gestão do Conhecimento na UFSC, quando fui inserida no Grupo de Estudo de Ambiente Hipermídia voltado ao processo de Ensino-Aprendizagem. Uma experiência enriquecedora e muito gratificante.

Sendo lançada para o primeiro semestre de 2016 e nominada como Acessibilidade digital, a disciplina contou com oito estudantes, onde seis deles eram docentes do ensino superior, tanto em instituições 
públicas federais quanto privadas. Uma das pessoas já contava com doutoramento, vindo cursa-la como disciplina isolada, pelo interesse que havia no conteúdo a ser trabalhado.

Essa primeira experiência em 2016, contou com a importante parceria da Prof. Dra. Vania Ribas Ulbricht, da UFSC, supervisora do citado pós doutoramento. Desta parceria, foi inserido também o então doutorando Raul Busarello (hoje doutor), e seguimos contando com as intervenções desses importantes parceiros.

Os alunos da disciplina receberam a tarefa de desenvolver OAs acessíveis e gamificados, com tema livre, que ao final do semestre deveriam ser apresentados em seminários, seguidos de elaboração de artigos que os descrevia, desde a fundamentação e concepção, ao produto final pós desenvolvimento. Estes artigos, foram corrigidos, conferidos, e, junto com os trabalhos oriundos de disciplinas similares, ministradas pela professora Vania, na UFSC e na UFPR, compuseram o livro digital Protótipos funcionais de objetos de aprendizagem gamificados e acessíveis, que está sendo lançado neste evento e disponível para download na Editora Pimenta Cultural (https://www.pimentacultural.com).

A experiência exitosa, nos incitou a adotar um critério mais ousado para condução da disciplina no ano de 2017. Decidimos faze-la conjuntamente com as disciplinas congêneres da UFSC e da UFPR. As equipes estão compostas por alunos das três instituições, e as aulas, acontecem online entre Florianópolis e Recife, estimulando o trabalho colaborativo à distância, tanto nas aulas, quanto na interação das equipes para o desenvolvimento dos trabalhos. Esta turma encontra-se em andamento, com término agendado para final do mês de junho e os trabalhos desenvolvidos nas equipes devem ser publicado no segundo semestre deste ano.

A fim de contextualizar este artigo, foi traçado um breve perfil dos alunos, quanto aos conhecimentos de entrada na disciplina, e sobre a experiência após cursa-la. Os resultados encontram-se apresentados a seguir, contemplando os alunos das duas turmas.

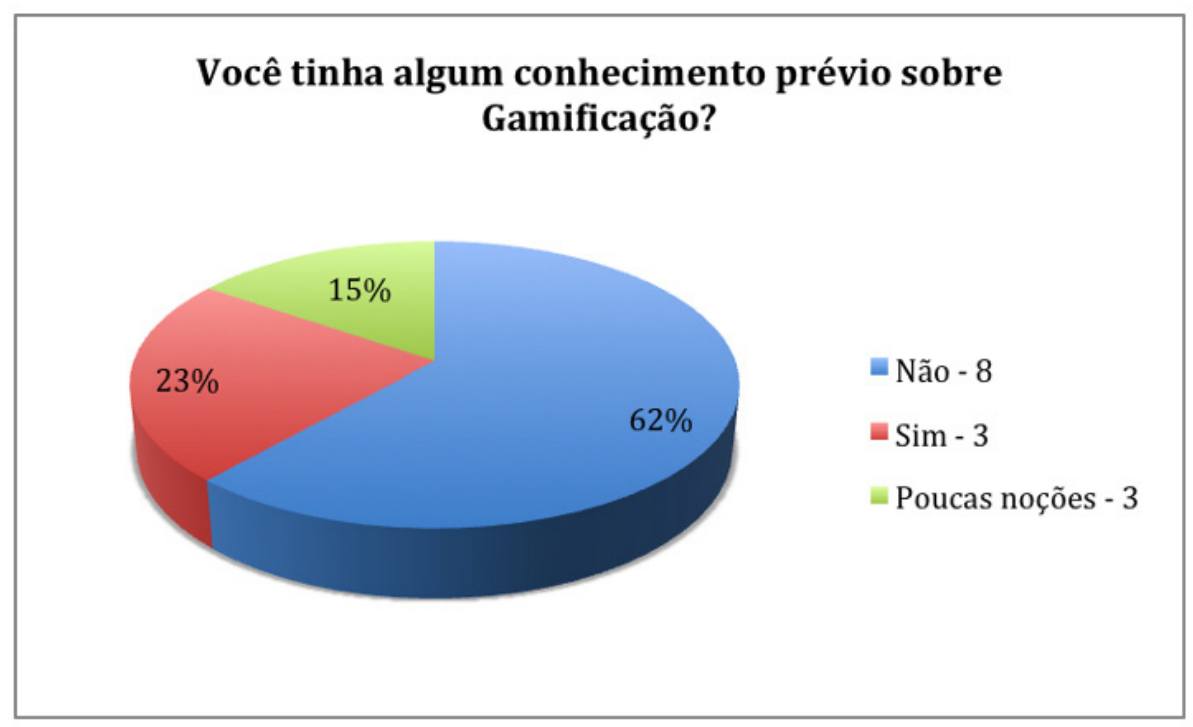

Gráfico 1: Pesquisa quanto aos conhecimentos iniciais dos alunos - Acessibilidade

Como se pode verificar no gráfico, a maioria dos estudantes não tinha conhecimentos prévios sobre a acessibilidade digital, seguidos de uma importante parcela com poucas noções sobre o tema. Apenas uma pessoa respondeu sim a esta pergunta.
O mesmo se registrou quando questionados quanto aos conteúdos da gamificação. Somente três pessoas estavam bem inteiradas da temática, como se vê no gráfico 02. 


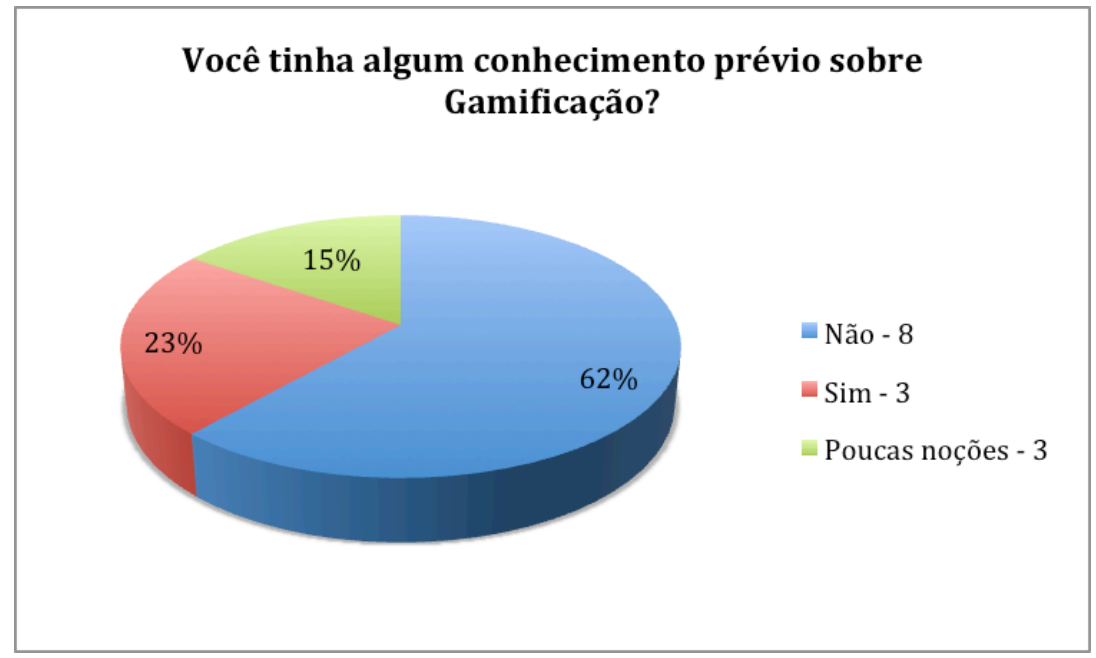

Gráfico 2: Pesquisa quanto aos conhecimentos iniciais dos alunos - Gamificação

Quando a questão foi centrada nos objetos de aprendizagem, se verifica que o índice de pessoas com conhecimento é ainda mais reduzido, ultrapassan- do $80 \%$ da turma sem nenhum conhecimento ou com poucas informações.

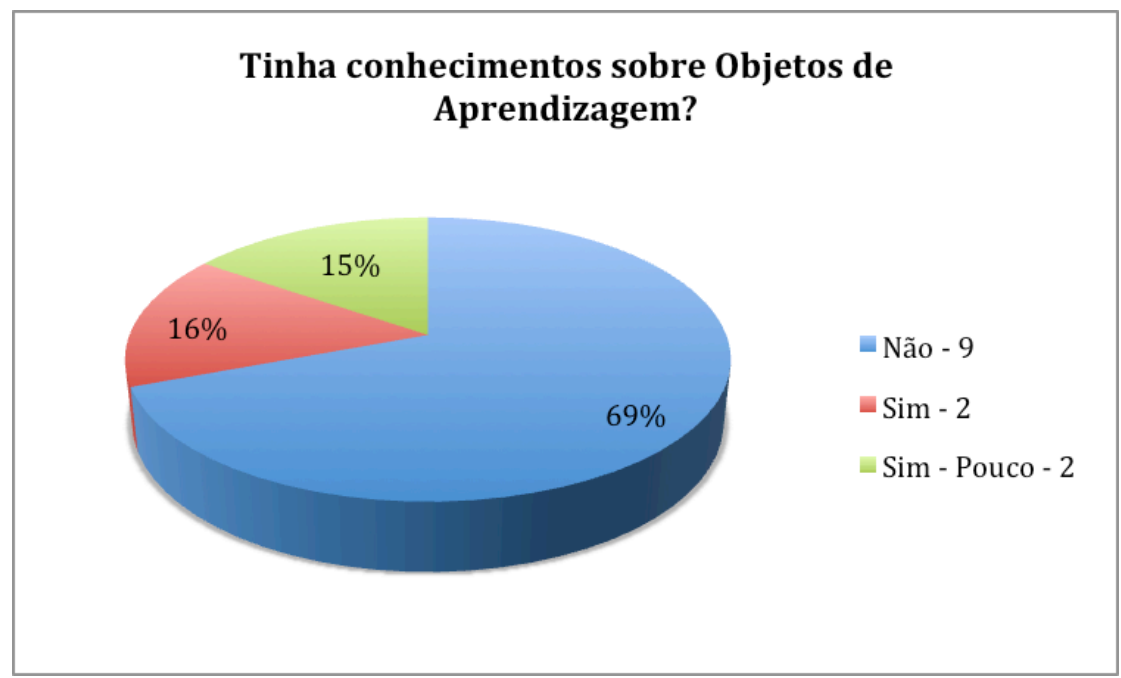

Gráfico 3: Pesquisa quanto aos conhecimentos iniciais dos alunos - OAs

Neste questionamento com resultados mostrados no gráfico 03, havia uma pergunta complementar sobre se já tinham elaborado algum para aplicação em meio digital, aos que disseram sim. Apenas uma pessoa tinha essa experiência prévia.
A última pergunta questionava sobre a experiência do estudante ao cursar a disciplina. A seguir estão transcritas as palavras que qualificavam a experiência: 
-Descoberta, interesse, desejo de continuar usando.

- Enriquecedora.

- Excelente, ótima prática.

- Proveitosa, irá contribuir para a vida profissional.

- Útil

- Interessante, será colocado em prática.

- Inovadora, construtiva.

- Excelente, já aplicando na vida profissional.

- Fundamental.

- Excelente.

- Positiva.

- Engrandecedora.

- Trouxe muita contribuição ao trabalho.

Tais resultados reforçam o excelente crescimento das turmas, quando se observam os protótipos desenvolvidos, a partir de pessoas que não possuíam familiaridade com os conceitos e fundamentos necessários à elaboração dos Objetos de Aprendizagem acessíveis e gamificados, solicitados como produto final da disciplina. Eles estão apresentados sucintamente no item 4 deste artigo.

\section{Sobre Acessibilidade e Gamificação}

O Histórico do Ensino à Distância (EAD) teve início com programa de televisão e Rádio. Nessa perspectiva, não existia um inclusão das pessoas com algum tipo de deficiência. Recentemente os EAD's contam com as ferramentas on-line e se dividem em dois grupos: o e-learning, que designa de forma geral os Cursos à distância on-line e os m-learning, nos quais o ensino é realizado através de dispositivos móveis. Contando com meios tão modernos para sua divulgação, as pessoas com deficiência podem ser incluídas mais facilmente (AMARAL et al, 2011).

No entanto, não é esse o quadro que vemos instalado. Ainda nos deparamos com fortes carências nesta área, mesmo considerando toda tecnologia disponível e importantes trabalhos que são desenvolvidos nas universidades e grupos de pesquisas.

Os trabalhos aqui apresentados trazem como uma das características principais serem acessíveis, tendo incorporados princípios e diretrizes adotados na acessibilidade digital.

Em sua tese de doutorado, Macedo (2010), propõe um conjunto de diretrizes para criação de objetos de aprendizagem acessíveis, com a intenção de orientar e contribuir com os professores conteudistas e desenvolvedores de objetos de aprendizagem, na elaboração de materiais acessíveis pela disponibilização de mídias alternativas ou equivalentes.
As diretrizes criadas são fundamentadas na análise e na convergência dos "Princípios de Design Universal”, com as "Recomendações de Criação de Conteúdo Acessível para web" do W3C, e com as "Melhores Práticas para Produção de Aplicativos e de Conteúdo Acessível” apresentadas nas guias do Instructional Management Systems (IMS). Web World Wild Web Community (W3C) - O World Wide Web Consortium $\left(\mathrm{W}_{3} \mathrm{C}\right)$ é a principal organização internacional de padrões para a World Wide Web (WWW abreviadas ou W3). (MACEDO, 2010).

Outro elemento presente nos protótipos desenvolvidos na disciplina foi a gamificação, que tem por princípio fazer com que o usuário se comporte como em um jogo, em situações do cotidiano ou que não são propriamente de jogo, onde os elementos retirados destes auxiliam para maximizar o engajamento e motivação dos usuários (FADEL et al, 2014). Estes aspectos são importantes principalmente quando se considera usuários com deficiência.

Gamificação pode ser aplicada à atividades em que é preciso estimular o comportamento do indivíduo e em circunstâncias que exijam a criação ou a adaptação da experiência do usuário a um produto, serviço ou processo. Buzarello (2016).

Kapp (2016) contribui nas questões da gamificação, Hariry (2015) no que diz respeito ao uso de mobile phone, como ferramenta de aprendizagem e os estudos de Thiesen (2008) tratam temáticas diversas de forma interdisciplinar. A conjugação destas contribuições podem garantir o interesse do usuário.

Agentes presentes em jogos, como personagem, competição e regras podem ter efeito direto na motivação da aprendizagem, conforme citam Schmitz, Klemke e Specht (2012) apud Buzarello (2016)

A gamificação está relacionda com a Teoria do Flow e a ideia geral é de que as pessoas envolvidas nas dinâmicas propostas sejam desafiadas o suficiente para que assim possam atingir o estado de Flow.

O desafio para o OA acessível e gamificado é proporcionar um estado de Flow, a partir do envolvimento total de quem o navega. Ao acessar os conteúdos e iniciar o trajeto gamificado, a vivência do Flow leva a um envolvimento onde toda a atenção está tão profundamente envolvida, que o indivíduo abstrai o mundo ao seu redor.

Estas são as principais características que os alunos deveria imprimir aos protótipos por ele desenvolvidos. 


\section{Os OAs produzidos na turma de 2016}

Neste tópico demonstramos os resultados alcançados na disciplina no semestre letivo 2016.1. Utilizamo-nos dos resumos constantes de cada artigo que expõe os OAs desenvolvidos, para apresenta-los aqui, exatamente como o mostram seus autores.

O pequeno grupo foi dividido em duplas que produziram quatro trabalhos.

- O AMMA - Amor maior - por Andrea Oliveira e Lizie Sancho

O trabalho constou do desenvolvimento de um aplicativo acessível como objeto de aprendizagem gamificado para o sistema operacional Android. O AMMA, como é denominado, tem como foco o ensino de pais de crianças com microcefalia à prática de atividades do cotidiano com seus filhos, bem como a construção de brinquedos e outros materiais que venham necessitar. A pesquisa teve um delineamento bibliográfico e de campo, ou seja, primeiro foi feita uma revisão da literatura para em seguida ser produzida uma pesquisa qualitativa com estes pais e profissionais da saúde que trabalham com o público-alvo; para em seguida, a criação da interface gráfica do aplicativo baseada nesses estudos, através de dois softwares: Balsamiq e o Adobe Experience. Acredita-se que a elaboração de um material que esteja disponível 24 horas por dia à qualquer pessoa que necessite desse conteúdo, poderá não só melhorar a qualidade de vida dessas crianças quanto ajudar em seu desenvolvimento.

Inserimos aqui algumas imagens que ilustram o Objeto de Aprendizagem, acessível e gamificado desta dupla, salientando que este protótipo vem se desenvolvendo após o encerramento da disciplina, alcançando e envolvendo organizações que efetivamente dão suporte aos pais de crianças com microcefalia.

Todas as imagens aqui apresentadas foram desenvolvidas pelas autoras do aplicativo.

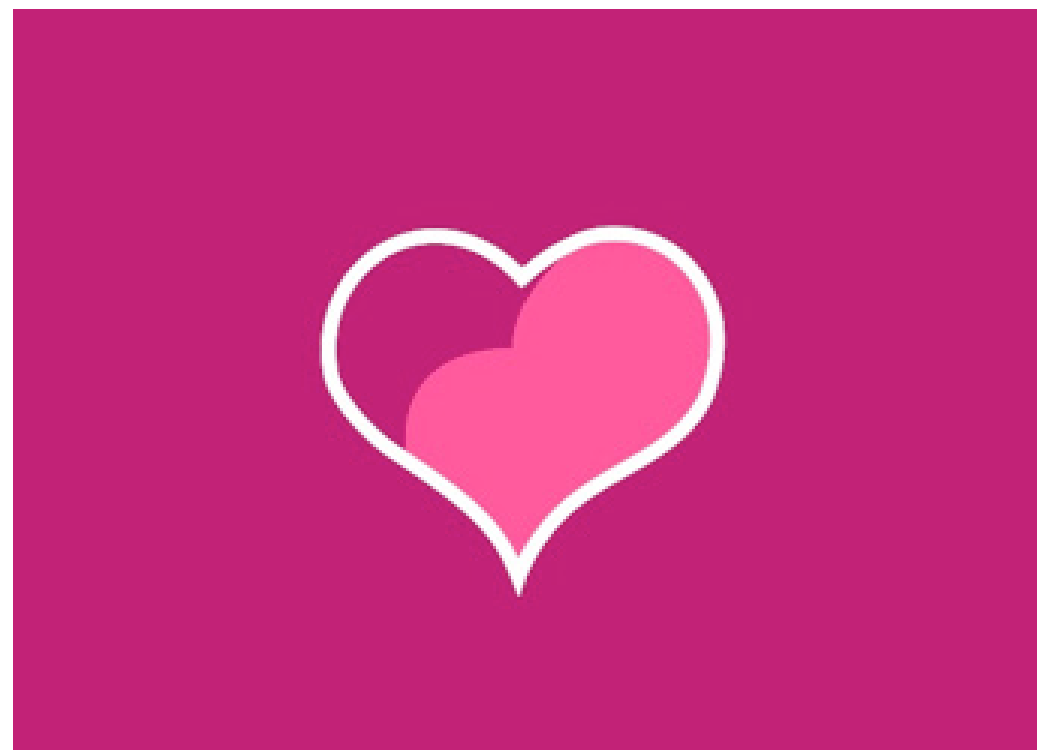

Figura 1: Marca do Aplicativo AMMA.

O protótipo foi desenvolvido conforme a inserção de diretrizes extraídas de Macedo (2010) e da W3C.

Sancho et all (2017) colocam que as mecânicas de jogos inseridas foram: pontos - que possibilita o acompanhamento e interação dos jogadores durante o jogo, podendo servir como estímulo para o jogador; níveis - indica o progresso do jogador mediante o jogo, sendo útil para medir a habilidade do jogador. 


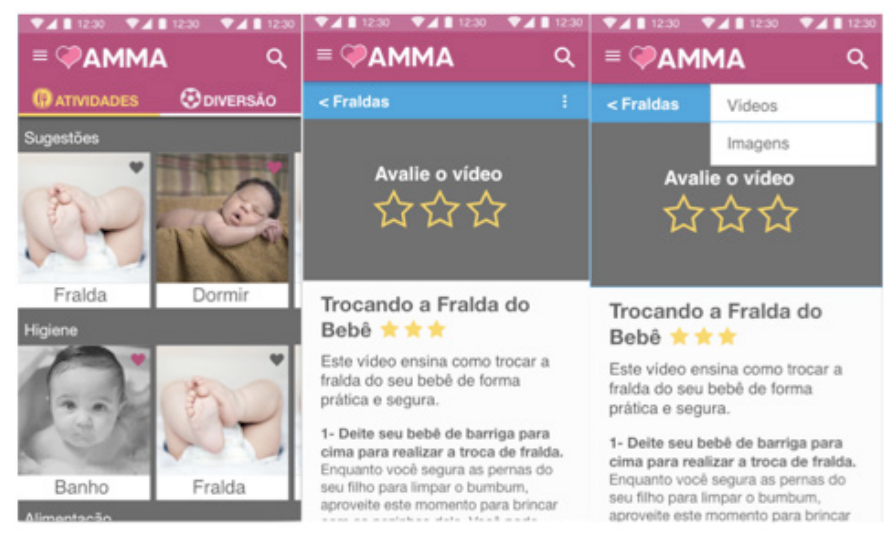

Figura 2: Telas do Aplicativo AMMA: destaque para os menus.

Continua com as divisas - que são os elementos simbólicos do jogo, ele aumenta o nível de engajamento; badges (medalhas), são os que correspondem aos emblemas, funcionando como um raking dos líderes; reforço e feedback - para oferecer mais envolvimento através dos dados computados pelo jogo.

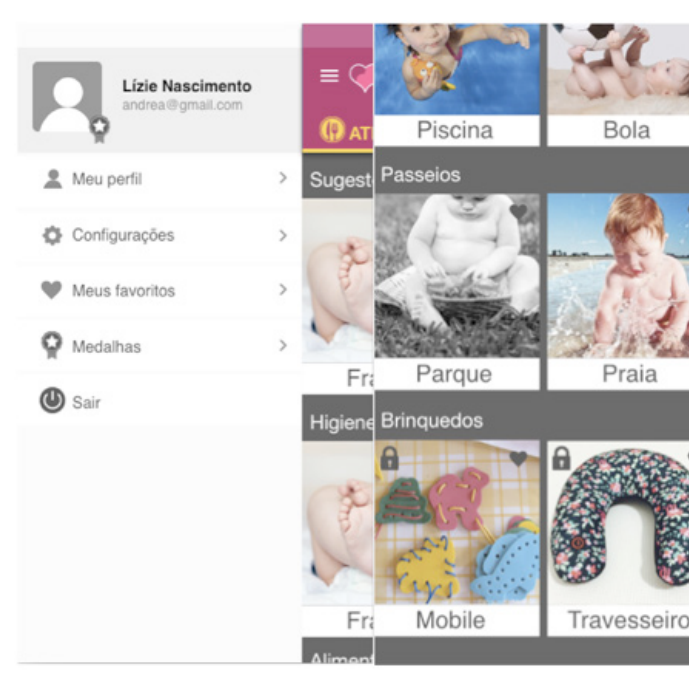

Figura 3: Telas do Aplicativo AMMA: destaque para os menus.

A complementação de desenvolvimento e validação do AMMA, está prevista como pesquisa de mestrado em design de uma das autoras. Está também envolvido na continuidade do desenvolvimento deste protótipo, o CREFITO-PE, Conselho de Fisioterapia e Terapia Ocupacional de Pernambuco.
- MESTRE SU - um objeto de aprendizagem acessível e gamificado para ensino da gastronomia oriental - por Ana Maria Maciel e Ester Costa

Este trabalho descreve o desenvolvimento de um objeto de aprendizagem (OA), gamificado e acessível na área de gastronomia. Embora a internet te- 
nha se tornado a mídia dominante no processo de ensino/aprendizagem, ao mesmo tempo que pode potencializar a educação inclusiva pode apresentar barreiras de acesso aos indivíduos que possuem algum tipo de desabilidade. Assim surgiu a proposta de um OA na área de formação em gastronomia, de modo a contribuir para a construção de artefatos virtuais acessíveis a todos os estudantes. A metodologia adotada tomou como base os pressupostos teóricos do Design Universal, da acessibilidade e da gamificação. O Design Universal na aprendizagem, busca permitir que cada aprendiz possa desempenhar suas atividades, valorizando suas habilidades e promovendo novas competências. Os recursos utilizados foram baseados nas recomendações de acessibilidade da $\mathrm{W}_{3} \mathrm{C}$. O Objeto de Aprendizagem foi projetado para que seja acessível para pessoas com cegueira e/ou baixa visão, com surdez, deficiência de cognição e motora. Para tornar o processo de aprendizagem mais lúdico e envolvente para os estudantes foram utilizadas estratégias de gamificação. Apresentamos um conjunto de reflexões que contribuem para o desenvolvimento de ambientes virtuais, capazes de ampliar o acesso de discentes deficientes ou não a conteúdos acessíveis e gamificados para aprendizagem.

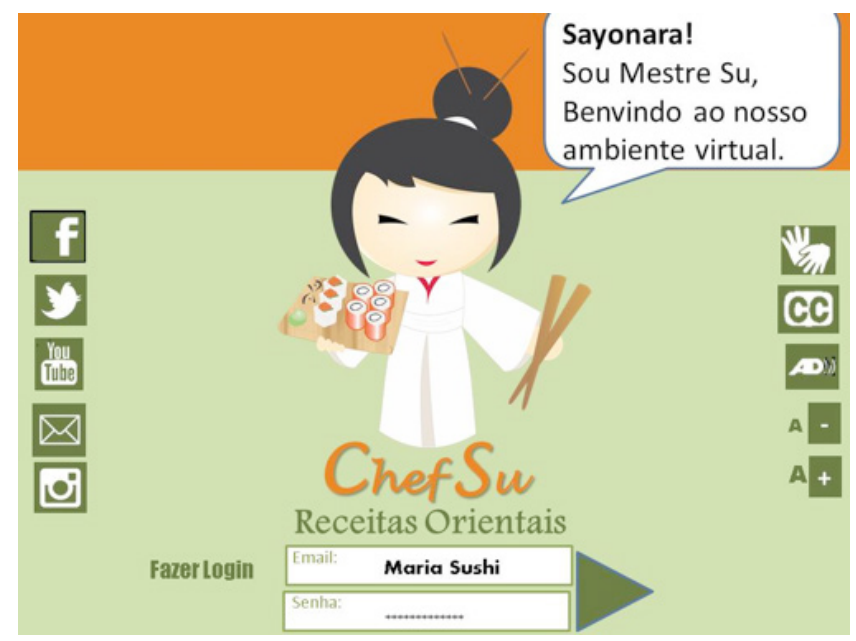

Figura 4: Estratégias de acessibilidade para deficiência cognitiva da tela 1.

O objetivo da proposta do objeto de aprendizagem Mestre SU aqui descrito é demonstrar que é possível, por meio do domínio de conhecimentos gastronômicos, que pessoas com deficiência possam adquirir mais autonomia quando se descobrem capazes de manipular alimentos para seu consumo próprio ou para o exercício de atividades profissionais. (Maciel e Costa, 2017).

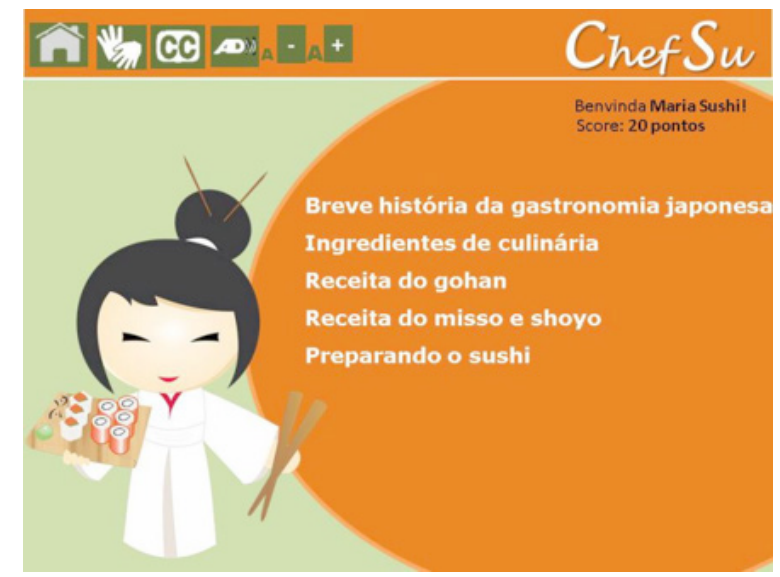

Figura 5: Parte teórica - tela inicial. 
Segundo as autoras, os textos inseridos ao longo das atividades são curtos e não existem links no meio dos textos, uma vez que as pessoas com deficiência visual podem confundir-se e reiniciar a leitura.

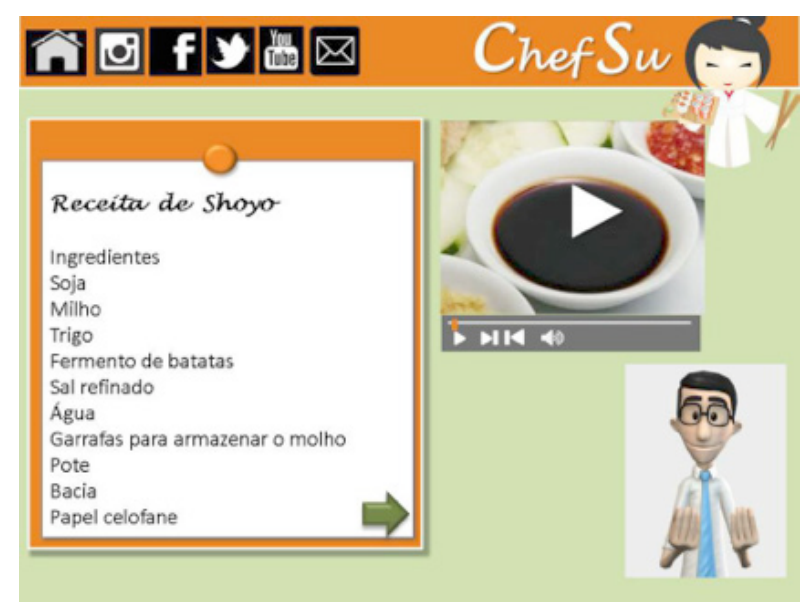

Figura 6: Estratégias de acessibilidade para deficiência auditiva (Uso do hand talk)

Elas explicam que não são utilizados arquivos em formato PDF, para apresentação do conteúdo principal ou complementar uma vez que dependendo da forma como foram produzidos são inacessíveis via leitores de tela.

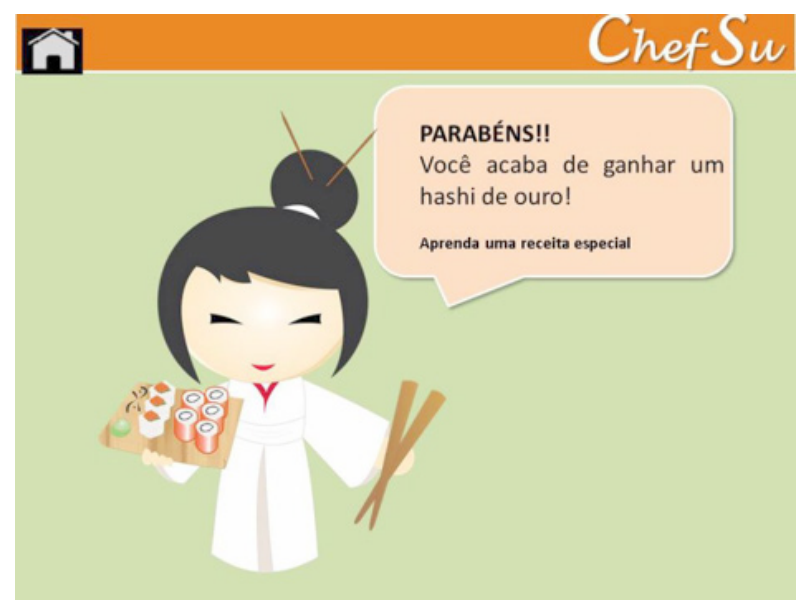

Figura 7: Elemento de gamificação - Recompensa

A competição acontece de duas maneiras: Através da superação do usuário consigo mesmo, com as "perguntas desafios" e entre os usuários do OA quando são desafiados com as missões, preparando as receitas e postando nas redes sociais. (Maciel e 
Costa, 2017). O objeto passou por uma testagem a partir de check list elaborado pelas autoras.

Todas as imagens aqui apresentadas foram desenvolvidas pelas autoras do aplicativo.

- GEOGRAM: ensino acessível e gamificado da geometria através do Tangram - por Andiara Lopes, Sadi Seabra e Vilma Villarouco.

Este trabalho foi desenvolvido durante e disciplina Acessibilidade Digital do Programa de Pósgraduação em Design da Universidade Federal de Pernambuco. A disciplina teve como meta o desenvolvimento de uma pesquisa para a criação de um Ambiente de Aprendizagem Acessível e Gamificado para o ensino de princípios de geometria através do
Tangram, voltado para o ensino a todas as pessoas, sejam elas deficientes visuais, auditivos - em diversos espectros - bem como pessoas sem deficiências. Para trabalhar com a Acessibilidade tomou-se como base os princípios do Design Universal e de Macedo (2010), dos quais foram utilizadas imagens em movimento e áudio-descrições que orientam o estudante a encaixar as peças do Tangram. Este trabalho é um desafio porque envolve três áreas da educação ainda em desenvolvimento: ensino à distância, Acessibilidade e Gamificação. Os resultados dessa pesquisa foram além do material didático produzido, podendo ser ainda utilizada como referência para a produção de conteúdo acessível em geometria e um incentivo para que seja repensado um ensino mais inclusivo.

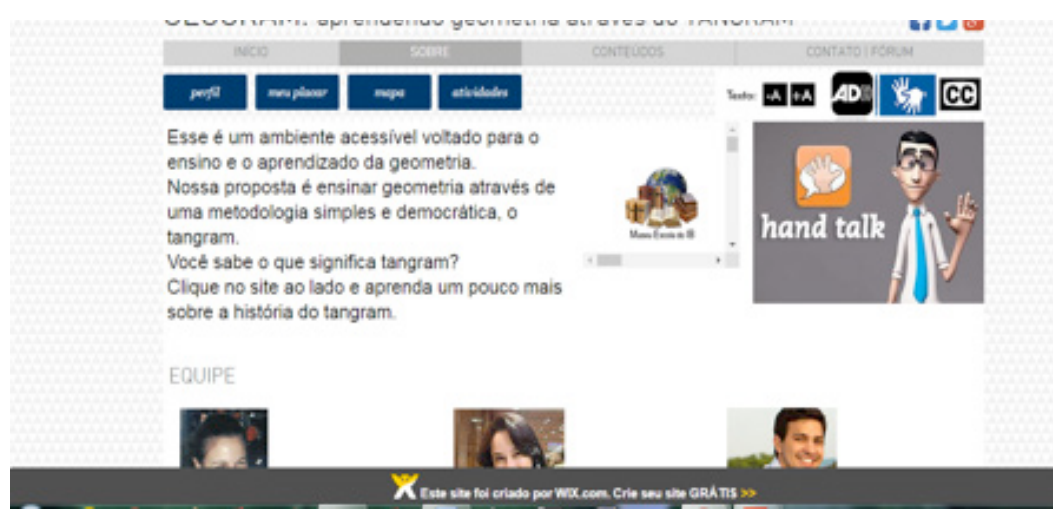

Figura 8: tela inicial simulado na plataforma Wix.com

Os autores colocam que por ser um ambiente onde várias telas podem ser impressas, para que o usuário utilize as silhuetas dos desafios do Tangram, o estudante pode apertar as teclas de atalho Ctrl+p para abrir as configurações de impressão. Tanto o Tangram como as silhuetas têm a possibilidade de serem impressos em impressoras específicas que imprimam com relevo. Todas essas fun- ções estão descritas na parte de dicas, deixando o usuário sempre consciente que pode utilizar dessas funções em qualquer momento. A seguir, a imagem do AVAA GeoGram com as telas do mapa da aventura e do desafio, nas quais o usuário navega para encontrar novas tarefas e acompanha sua trajetória.

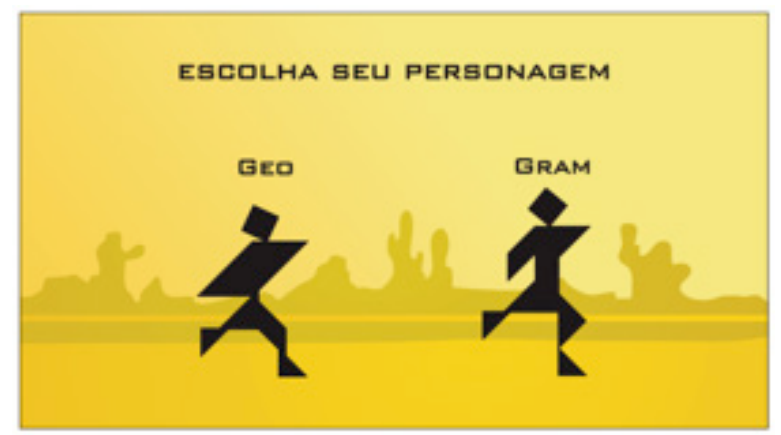

Figura 9: Tela da escolha dos personagens Geo e Gram. 
Na tela da figura 10, o personagem recebe as orientações do Imperador Tan para construir um Tangram próprio que servirá para superar os desafios e aprender os conceitos geométricos.
Este AVAA foi pensando para usuários de 12 a 17 anos que estejam no ensino fundamental e médio, podendo ser estendido para qualquer pessoa que não possua conhecimentos básicos em geometria.

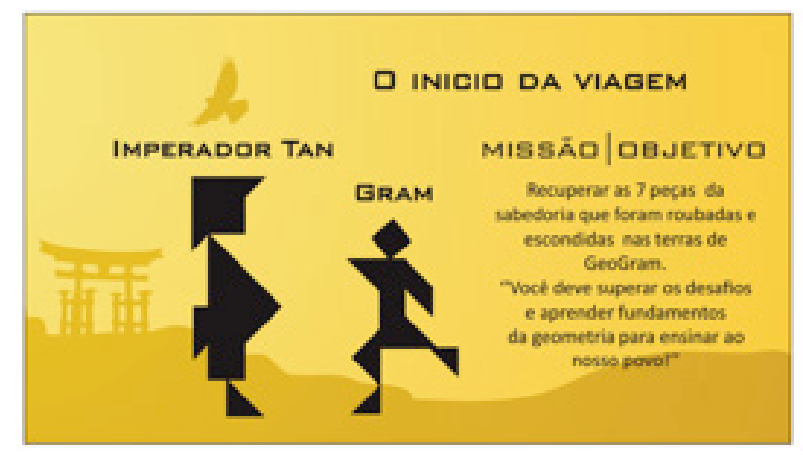

Figura 10: O início da viagem.

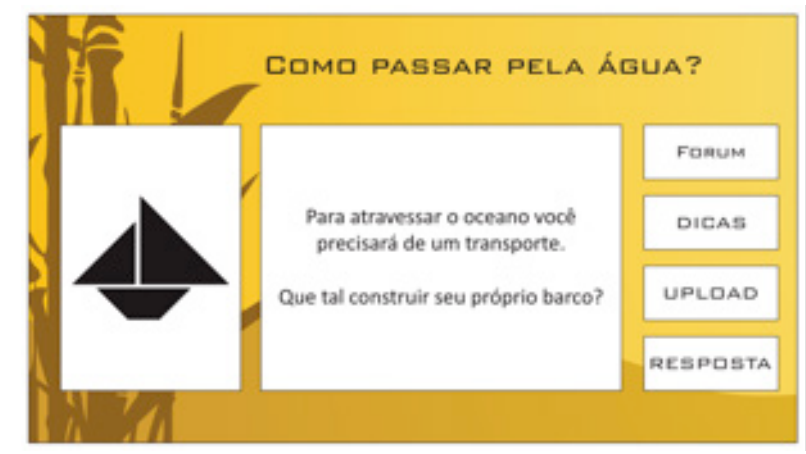

Figura 11: Desafio da construção do barco para transporte pelos oceanos

O ambiente é planejado, para que pessoas com deficiência ou não, possam aprender e se apropriar dos conhecimentos geométricos tão fundamentais para a vivência diária.

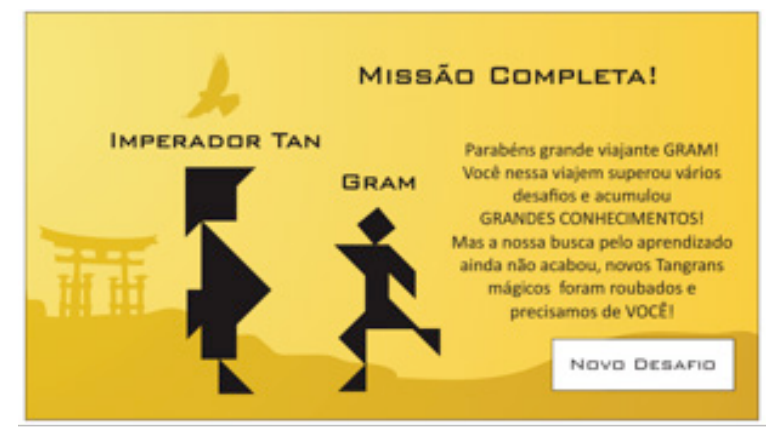

Figura 12: Tela de Missão Completa. 
Todas as imagens aqui apresentadas foram desenvolvidas pelos autores do AVAA.

- O DIA EM QUE EINSTEIN NÃO SABIA: objeto de aprendizagem sobre Revisão Sistemática da Literatura - por Rafaela Sobral e Ana Katharina Leite.

O cenário educacional da pessoa com deficiência reflete a latente necessidade de estratégias e recursos que tornem o conteúdo pedagógico acessível e motivador. Considerando em especial, estudantes de nível superior que vivem tal contexto, o presente capítulo descreve a proposta de um objeto de aprendizagem acessível e gamificado sobre Revisão Sistemática da Literatura, método executado em 7 etapas criteriosas para busca e análise de evidên- cias científicas. A proposta do ambiente virtual de aprendizagem em questão, está respaldada em conceitos e teorias de acessibilidade e gamificação que tornam o objeto factível de futura implementação, delineando-o como uma ferramenta útil no processo de ensino-aprendizagem para estudantes com e sem deficiência. Aborda-se aqui o processo de criação de um modelo inicial de alta fidelidade de um Objeto de Aprendizagem (OA) em um Ambiente Virtual de Ensino e Aprendizagem Acessível (AVEA), sendo fruto da disciplina de Acessibilidade Digital vinculada ao programa de pós graduação em Design da UFPE.

Todas as imagens aqui apresentadas foram desenvolvidas pelas autoras do aplicativo.

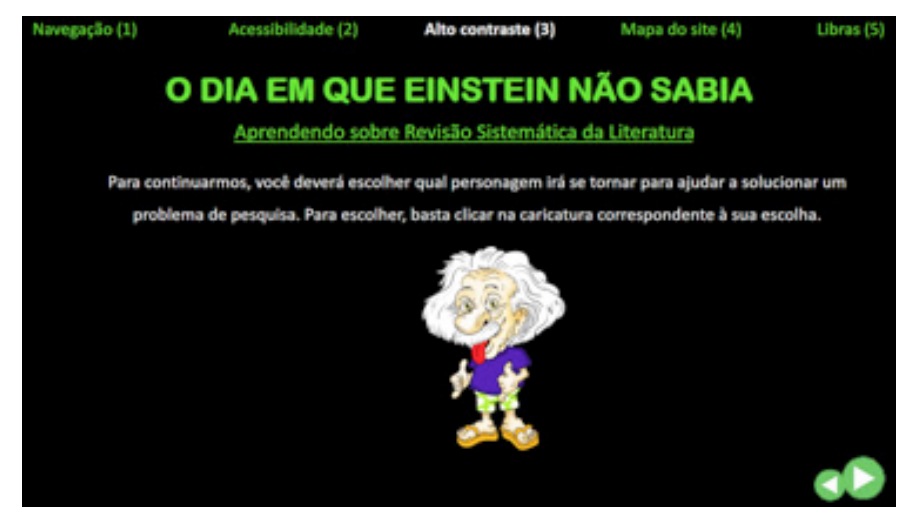

Figura 13: Tela função de alto contraste

O OA conta uma estória que Einstein não sabia fazer revisão sistemática e pra isso precisava ser ensinado através do protótipo que foi desenvolvido.

As autoras expõem que foi estruturada uma narrativa que busca provocar a identificação do usuário através de situações semelhantes vivenciadas por ele e também abordadas pela narrativa. Para tanto, foram escolhidas duas personagens: Albert Einsten e Stephen Hawking. Esses personagens foram selecionados considerando o público-alvo que utilizará o objeto de aprendizagem: como o OA busca ensinar a RSL, considera-se que seus usuários serão estudantes de graduação, pós-graduação e pesquisadores, sendo estes usuários mais experientes, que possuem conhecimentos prévios acerca de pesquisas científicas.

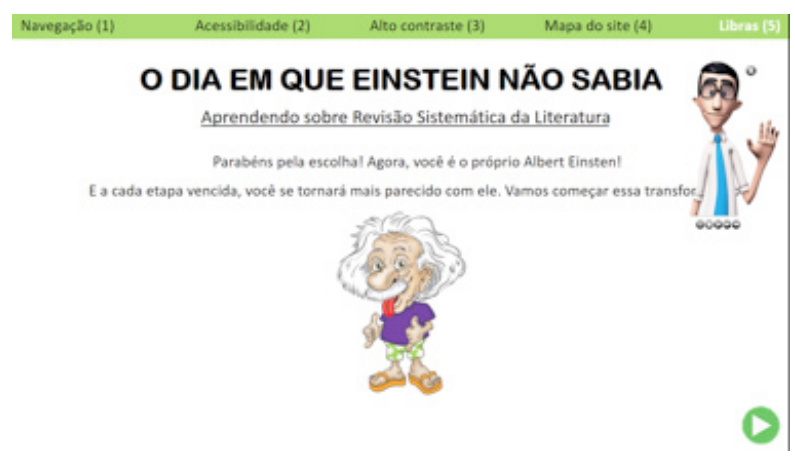

Figura 14: Tela com a função libras 
O jogo propõe que a fotografia do usuário, fornecida no cadastramento, vá recebendo características dos personagens à medida que os desafios forem superados com acertos. O objetivo estará alcançado, quando a imagem do aprendiz assemelhar-se ao personagem escolhido.

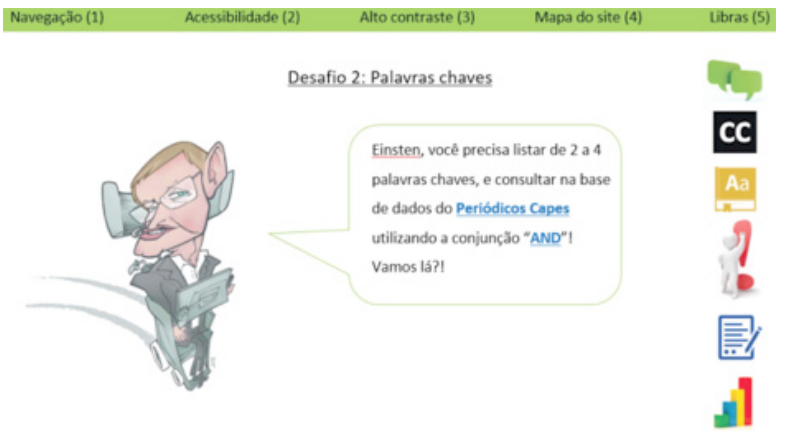

Figura 15: Tela com a função libras

A nova forma de comunicação e expressão que surgiu com a inserção das redes sociais no cotidiano das pessoas faz com que o usuário deseje compartilhar imagens, experiências, vídeos e momentos.
Assim, a cada elemento adquirido da caracterização do personagem o usuário poderá fazer o download da figura e/ou compartilhá-la em suas redes sociais, como consta nas imagens acima.

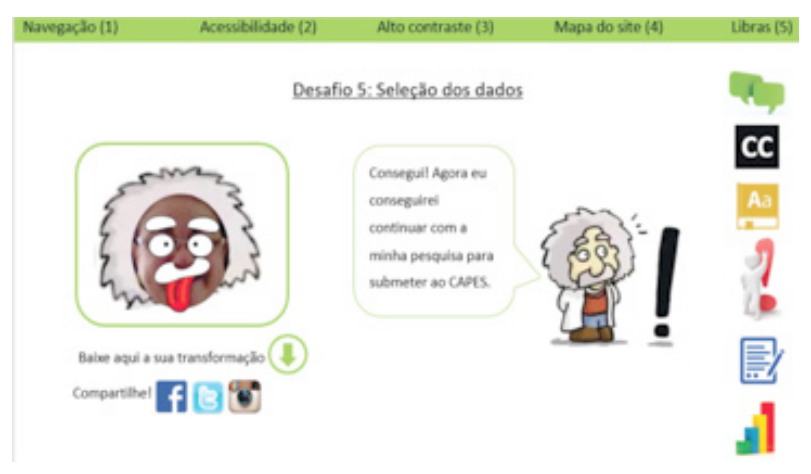

Figura 16: Exemplo de premiação com transformação na foto

Essa forma de recompensa foi estruturada para aumentar o engajamento dos usuários, fazendo com que eles se sintam estimulados a conquistar uma nova fase e, consequentemente, mais uma característica do personagem escolhido.

A gamificação confere o sentimento de competição consigo mesmo. As mais recentes ferramentas para sistemas Android e IOS trazem incorporadas técnicas gamificadas, onde à medida que o aplicativo é usado gera acumulo de pontuação, conferindo categorias crescentes ao usuário.

\section{Comentários Finais}

A experiência aqui relatada alcançou excelentes resultados na turma de 2016 e vem igualmente sendo 
bem sucedida na turma de 2017 em andamento, mesmo registrando o quase total desconhecimento dos temas tratados, conceitos e técnicas, utilizadas na produção dos protótipos de objetos de aprendizagem desenvolvidos pelos estudantes.

As questões da atribuição de investigações aos estudantes em situações de ensino vem sendo pesquisada e testada há décadas.

Conforme Moreira (1983), já nos anos 80, a resolução de problemas que leva a uma investigação deve estar fundamentada na ação do aluno. Os alunos devem ter oportunidade de agir e o ensino deve ser acompanhado de ações e demonstrações que o levam a um trabalho prático.

As tecnologias emergentes trazem novos conceitos e práticas nas relações de ensino e aprendizagem. No entanto, apesar de esforços de inserção da tecnologia nas salas de aula mais tradicionais, ela continua sendo o local onde há dois atores: o professor, que fala, demonstra, expõe - ainda que utilizando novíssimas tecnologias, e os estudantes que observam e ouvem. A sala de aula tradicional está geometricamente alinhada, e possibilita uma maior distância entre estudantes e professor. Piva Jr. e Cortelazzo (2015).

No caso da disciplina de Acessibilidade Digital, a despeito de estar constituída por alunos de pós-graduação, os processos de investigação e participação ativa deveriam estar intrínsecos. No entanto, a cultura sedimentada na formação de muitos estudantes, os faz aguardar pelo estímulo do professor, agendando trabalhos a serem desenvolvidos e entregues.
Não podemos considerar que temos adotado os princípios da Sala de Aula Invertida ou "Flipped Classroom" em nossas aulas. Este, preconiza que a teoria deva ser vista pelos estudantes em casa, previamente à “aula”. Em sala de aula, presencialmente, as dúvidas e os exercícios de aprofundamento e/ou aplicação, são desenvolvidos em conjunto com os professores. Nesse processo, o professor é mais um orientador, estimulador, norteador, do que simplesmente um "passador de conteúdo". Piva Jr. e Cortelazzo (2015).

Mesmo não tendo ainda implantado este modelo, adotamos a estimulação para que o aprendizado seja alcançado a partir da prática. Se apenas nos limitássemos às aulas teóricas, com a distribuição de informações a partir do professor, não teríamos o desenvolvimento dos significativos objetos de aprendizagem acessíveis e gamificados, que ajudam a sedimentar os conteúdos estudados.

A motivação e interesse dos alunos são notáveis e refletem-se na consolidação dos conhecimentos, quando se encontram aplicados nos protótipos desenvolvidos.

A parceria com o Grupo de Estudo de Ambiente Hipermídia voltado ao processo de Ensino-Aprendizagem da Universidade Federal de Santa Catarina, tem sido fundamental. Esse grupo conta com uma larga experiência na área foco da disciplina e deste artigo, com um reconhecido trabalho e uma vasta produção qualificada.

\section{Referências Bibliográficas}

AMARAL, Marília; GONÇALVES, Marília e BATISTA, Claudia. Modelagem do Usuário e
de domínio por meio de mapas conceituais. In: ULBRICHT, Vânia, VANZIN, Tarcísio e
VILLAROUCO, Vilma. Ambiente virtual de aprendizagem inclusivo. Florianópolis: Pandion, 2011.

BUSARELLO, Raul Inácio. Gamification: princípios e estratégias. São Paulo: Pimenta Cultural, 2016.

FADEL, Luciane Maria, et al. Gamificação na Educação. São Paulo: Pimenta Cultural, 2014. 300 p. Disponível em: <http://www.pimentacultural.com/\#!gamificacao-na-educacao/c241i> Acesso em 15 abr 2016.

HARIRY, Nashwa A. E. Mobile Phones as Useful Language Learning Tools. European Scientific Journal, vol 11, n. 16, p. 298-317, June 2015.

KAPP, K. M. Choose your Level: Using Games and Gamification to Create Personalyzed Instruction. In MURPHY, M.; REDDING, S.; TWYMAN, J. (Eds.). Handbook on Personalized 
Learning for States, Districts, and Schools, 2016, pp. 131-143, Philadelphia, PA: Temple University, Center on Innovations in Learning. Retrieved from www.centeril.org

LOPES, Andiara V. SEABRA FILHO, Sadi S. VILLAROUCO, Vilma. GeoGram: ensino acessível e gamificado da geometria através do Tangram. In ULBRICHT, Vania, VILLAROUCO, Vilma, FADEL, Luciane (orgs.). Protótipos funcionais de objetos de aprendizagem gamificados e acessíveis. São Paulo: Pimenta Cultural, 2017.

MACEDO C. M. S. Diretrizes para a criação de objetos de aprendizagem acessíveis. Tese de Doutorado (Programa de Pós Graduação em Engenharia e Gestão do Conhecimento - PPEGC), Universidade Federal de Santa Catarina. Florianópolis, 2010.

MACIEL, Ana Maria M. JORGE, Ester R. da Costa. MESTRE SU: um objeto de aprendizagem acessível e gamificado para ensino da gastronomia oriental. In ULBRICHT, Vania, VILLAROUCO, Vilma, FADEL, Luciane (orgs.). Protótipos funcionais de objetos de aprendizagem gamificados e acessíveis. São Paulo: Pimenta Cultural, 2017.

MOREIRA, M. A. Uma abordagem cognitivista ao ensino. Porto Alegre: Editora da Universidade, 1983.

PIVA Jr., Dilermando, CORTELAZZO, Angelo Luiz . Sala de aula invertida, ambientes de aprendizagem e educação online: a junção de três métodos para potencialização do ensino de algoritmos. Anais dos Workshops do IV Congresso Brasileiro de Informática na Educação . CBIE-LACLO 2015.

DOI: $10.5753 /$ cbie.wcbie.2015.1271

SANCHO, Lizie, OLIVEIRA Andréa, MARTINS, Laura. AMMA: o desenvolvimento de um app acessível como objeto de aprendizagem para auxílio à pais de crianças com microcefalia. In ULBRICHT, Vania, VILLAROUCO, Vilma, FADEL, Luciane (orgs.). Protótipos funcionais de objetos de aprendizagem gamificados e acessíveis. São Paulo: Pimenta Cultural, 2017.

SOBRAL, Rafaela, LEITE, Ana Katharina. O dia em que Einsten não sabia: objeto de aprendizagem sobre Revisão Sistemática da Literatura. In ULBRICHT, Vania, VILLAROUCO, Vilma, FADEL, Luciane (orgs.). Protótipos funcionais de objetos de aprendizagem gamificados e acessíveis. São Paulo: Pimenta Cultural, 2017.

THIESEN, Juares da S. A interdisciplinaridade como um movimento articulador no processo ensino-aprendizagem. Revista Brasileira de Educação, v. 13, n. 39, pp. 545- 598, set/dez 2008.

ULBRICHT, Vania Ribas, VILLAROUCO, Vilma, FADEL, Luciane (orgs.). Protótipos funcionais de objetos de aprendizagem gamificados e acessíveis. São Paulo: Pimenta Cultural, 2017.

W3C WCAG 2.0. Web Content Accessibility Guidelines WCAG 2.o. W3C WAI, 11 dezembro 2008. Disponivel em: http://www.w3.org/TR/WCAG20/ 